\title{
The Importance of Leadership Diversity: The Relationship between Diversity and Organizational Success in the Academic Environment
}

\author{
Mark D. Winston
}

In the academic community, efforts to foster diversity are generally supported by a rationale that relates to equity and changing societal demographics. Private sector research, however, indicates support for a rationale relating to overall organizational success. Such research forms the basis for the consideration of the relationship between diversity and organizational success in the academic environment. In addition, the research provides evidence that diversity continues to be valued in the private sector, which employs many of the graduates whose academic preparation is supported by the college or university library. This article presents the results of a research study involving diversity and organizational success in the academic environment. The results provide evidence that there is a relationship between diversity and organizational success and offers further support for the results of the prior research in this area, as well as offering data to enhance the rationale for the support of diversity efforts in the academic library community.

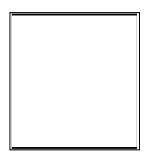
ostering diversity in organizations is generally considered a priority in relation to the increasingly diverse population, as well as past inequities, current unfairness, and underrepresentation. However, cutting-edge research in the study of diversity in the private sector has highlighted a documented connection between investment in diversity and overall organizational success and performance. In many organizations, and certainly in the private sector, specifically, there is the realization among managers and researchers that the reasons for promoting and fostering diversity within organizations go beyond the fact that it is a good thing to do. In other words, there are fundamental, practical, fiscally responsible reasons for fostering diversity that complement the rationale associated with social responsibility and equity, as organizations strive for success in an increasingly diverse society.

However, the study of diversity has not led to the identification of a direct, causal relationship between fostering diversity and organizational success. Thus, it seems that the study of diversity requires further consideration of the nature

Mark D. Winston is Assistant Professor in the School of Communication, Information and Library Studies at Rutgers University; e-mail: mwinston@scils.rutgers.edu. 
of the relationship between diversity and organizational success or performance. This article addresses the study of that relationship within the context of the academic environment.

\section{Background and Review of the Literature \\ Organizational Success and Diversity}

Researchers in organizational theory have documented the fact that the companies that are the most diverse, as measured by factors such as minority employment at all levels, spending with minority suppliers, and underwriting business that goes to minority-owned investment banks, have also been identified as more successful companies overall. ${ }^{1}$ Stock performance has generally been used as the measure of organizational success in such research. Stock performance might be considered as a measure of factors such as organizational performance, strength of the company, and investor confidence, among other considerations. For example, in the 1999 Fortune magazine article identifying "America's Best Companies for Minorities," the researchers reported rankings that indicate that the "companies that pursue diversity outperform the S\&P 500."2 Sherry Kuczynski reported similar results in her research, addressing what she described as "a direct link between a company's leadership diversity and its stock market performance." ${ }^{3}$ Kuczynski emphasized the fact that "One hallmark of successful diversity programs is diverse company leadership."

In providing an initial explanation for this relationship between diversity and organizational performance, Kuczynski noted that "Diverse leadership suggests that a company has drawn a wide pool of talent up through its ranks and is opening itself up to a variety of different views and ideas." ${ }^{5}$ This leadership diversity involves the relationship between organizational success and membership on the company's board and in senior managerial positions, among other positions. There is-and should be-continuing study of the nature of that relationship, which has not been fully defined. There is speculation that enhanced creativity results from varied perspectives, that specialized markets are easier to target, and that consumers are more aware and concerned about the performance, social responsibility, and composition of the companies they patronize, thus influencing overall organizational performance and success. ${ }^{6}$

It also is important to note that issues of underrepresentation, equity, and fairness should continue to be considered, in addition to other measures of performance.

Indeed, if boosting the bottom line was the only reason to increase diversity, some leading companies might wonder why they should carry their diversity programs any further than they already have. There are well-run companies that do not rank among the diversity leaders, as measured by the increasingly popular 'best' lists.... A continuing tight labor market may give companies more of a financial reason to boost diversity. ${ }^{7}$

In addition, growing corporate competitiveness, the unprecedented changes in the demographics of U.S. society, and the increasing globalization of marketplaces are likely to change the landscape dramatically and to provide continuing support for diversity programs. In a number of sectors, such as health care, for example, researchers and managers have begun to apply the study of leadership diversity to better assess organizational environments and performance and to make changes necessary to enhance the likelihood of success. ${ }^{8}$

\section{Theory}

It might be assumed that the concept of leadership diversity implies the initial formation of a theoretical construct involving the nature of the relationship between investment in and efforts to foster diversity and organizational success. 
Generally, leadership theory, which focuses on the study of the ways in which individuals can influence the success of organizations, through their efforts and those of others, provides a worthwhile basis for the consideration of issues of diversity as related to organizational success. Issues of diversity in relation to leadership have been addressed to a limited extent in the research literature, in relation to "gender and race differences. Other things being equal, men and women and those in different racial and ethnic backgrounds are equally effective as leaders." ${ }^{\prime 9}$ Moreover, research in this area has involved cross-cultural studies of leadership that are intended to determine whether certain leadership theories or approaches are culturally based. ${ }^{10}$

\section{The issue of realism or pragmatism associated with contingency theory relates to diversity in more than one way.}

It is generally the case that leadership theory relates to the study of the leader or to the study of the followers, in a more general sense, with some theories focusing more on the context. For example, a significant body of literature focuses on the extent to which the leader's personal qualities, such as intellectual ability, power, charisma, and virtue, and the leader's ability to influence followers, as a result of his or her values, for example, are the bases for effective leadership in organizations and more broadly. ${ }^{11}$ Leader-member exchange theory, for example, "holds that the manager's efficiency and effectiveness are affected by the quality of the relationship he or she has with each subordinate."12 The issue of context, beyond and including the leader and the followers, is considered in relation to aspects of leadership theory, as well. ${ }^{13}$ Historical determinism, for example, purports that it is the historical context, or the needs of the time, that "create the leader."14 The issue of context, particularly in relation to the environment, is considered in relation to theories such as transformational leadership, administrative conservatorship, and ecovision, as well. ${ }^{15}$ However, it appears to be the case that the aspect of leadership theory that relates most closely to leadership diversity is contingency theory, which is "also called pragmatism, realism, and Realpolitik." ${ }^{16}$ Contingency theory is based on the concept that the achievement of leaders' goals requires varying "styles and approaches depending on what will most effectively allow them to achieve" those goals. ${ }^{17}$

The issue of realism or pragmatism associated with contingency theory relates to diversity in more than one way. There is the well-documented aspect of realism associated with the changing demographics and increasing diversity of the U.S. population and the impact that these changes will have on the workforce and the marketplace. In addition, among managers, certainly within the private sector, as has been noted, there is the issue of pragmatism associated with being competitive and successful in targeting an increasingly diverse market and employing the type of individuals who will contribute to organizational success in this changing environment.

Also, with regard to realism or pragmatism, there is the importance of the role of colleges and universities in the preparation of the future graduates who will make up the well-prepared workforce that contributes to the success of the employing organizations, as well as the realization among those in society at large of this role. A significant research finding emerging in relation to diversity in higher education is based on the Ford Foundation's Campus Diversity Initiative and other research, indicating the central role of "colleges and universities [in] prepar[ing] people to function in a diverse society."18 In other words, when queried about issues related to the value of diversity as a societal issue, most people appear to realize its importance and value and indicate an understanding of the role of colleges and universities in preparing students to function in a diverse society. It is important to note that despite con- 
flicting court decisions and policy decisions related to diversity, the research indicates that most members of the public, like managers in organizations and organizational researchers, understand the importance of fostering diversity. ${ }^{19,20}$

Thus, the nature of the competitive, increasingly diverse, and evolving environment indicates that leaders must use techniques that will most effectively address the dynamic nature of that environment and that will represent pragmatism in realizing organizational success in this context.

\section{Organizational Success and Diversity in the Academic Environment}

The Fortune study and the related research involving the connection between organizational success and diversity in the private sector provide a worthwhile basis for studying such a relationship in the academic library environment. This is the case, particularly in light of the role of colleges and universities in preparing future graduates and the extent to which the academic library is a part of the research and education in all disciplines.

In the study of diversity and organizational success in the academic environment, considering the college- or university-level parent institutions instead of the libraries per se is appropriate initially because the parent institutions are more directly comparable to the companies (i.e., parent companies) evaluated and ranked in the Fortune study and related research. Based on the fact that more published data are available in relation to parent institutions - colleges and universities in this case as opposed to the libraries-as is also the case in the private sector, it was determined that this initial research related to the relationship between organizational success and diversity in the academic community would focus on the larger institutional level. The published research related to colleges and universities includes more comprehensive, established data regarding institutions overall and in relation to diversity. In addition, although there is little published research related to diversity in liberal arts colleges, for example, there is even less in relation to liberal arts college libraries.

In the case of academic libraries, although organizational success might be considered in relation to factors such as use, quality, and user satisfaction, the few rankings based on measures of organizational success include the Chronicle of Higher Education rankings, which focus on collection size and growth, but not on collection quality or quality overall, or data published by the Association of Research Libraries, which generally do not identify institutions by name in relation to performance or success involving diversity. ${ }^{21,22}$

In addition, there are data that indicate that with regard to the connection between the larger organization and the library in terms of diversity, there is a connection between the influence of efforts at the college or university level and efforts undertaken in the library. ${ }^{23}$ Thus, the study of the relationship between organizational success and diversity at the institutional level informs the study of diversity in academic libraries and forms the basis for further consideration of these issues in college and university libraries.

To address the relationship between organizational success and efforts to foster diversity, it is necessary to identify appropriate measures of success and diversity for such a study. The published research related to the comparison of colleges and universities on various measures of organizational success is quite extensive. One well-known example, The Princeton Review: The Best 331 Colleges, has been published for many years and focuses mainly on student evaluations of various aspects of the academic experience, as well as other statistical information. ${ }^{24,25}$ The Princeton Review publication includes rankings of institutions of various types, such as research universities and liberal arts colleges, that are compared with one another. "The Top American Research Universities: An Occasional Paper from the Lombardi Program on Measuring University Performance," pro- 
vides rankings of the top private research universities and top public universities. ${ }^{26}$ The Lombardi study considers criteria such as research funding, faculty, and degrees awarded but has been published in its entirety only once. ${ }^{27}$

The U.S. News and World Report rankings of colleges and universities provides specific rankings of quality-measures used to define "academic excellence"-including academic reputation, graduation, freshman retention, faculty resources, class sizes, student/faculty ratios, percentage of full-time faculty, SAT / ACT scores, acceptance rates, financial resources, and alumni giving, for various types of institutions (liberal arts colleges, national universities, national public universities, as well as regional universities). ${ }^{28,29}$ Although the U.S. News rankings are based on a methodology that has been tested and validated over time, the editors indicate that because the methodology may undergo some "refinement" from year to year, they "do not invite readers to track colleges' annual moves in the rankings." ${ }^{\prime 30}$

There are few published rankings of college and university performance in relation to diversity. Generally, rankings of this type focus on enrollment or graduation rates for members of particular ethnic groups, such as Hispanics, in the publication "Colleges Awarding the Most Bachelors Degrees to Hispanics" and on similar rankings related to Asian Americans and African Americans. ${ }^{31-33}$ The U.S. News and World Report publication, however, includes diversity rankings that focus on minority enrollment overall and provides such rankings in relation to various types of institutions, with similar types of institutions compared with one another. The rankings are determined on the basis of "a formula that factors in both the total proportion of minority students at a university-not including international students-and the mix of racial and ethnic groups....The formula produces a diversity index that ranges from 0.0 to 1.0 . The closer the index is to 1.0 , the more diverse is the student body." ${ }^{\prime \prime}$
Generally, the research related to diversity in libraries focuses on issues of staffing, collections, services, and organizational climate. ${ }^{35}$ The focus of research related to diversity in college and university libraries has been mainly libraries in research universities, with limited discussion of liberal arts college libraries, where the level of activity in relation to diversity programs has not been overwhelming. ${ }^{36,37}$ Thus, further study of this important segment of the academic environment is appropriate. And it was determined that liberal arts colleges would be the focus of this study.

The purpose of the research presented here is to address the extent to which there is a relationship between organizational success and diversity efforts in liberal arts colleges. Thus, the research not only provides a basis for determining the extent to which there is a relationship between diversity and organizational success in an important segment of the academic environment, as there is in the private sector, but it also provides a basis for further study related to academic libraries, particularly considering whether there is a correlation between college or university success and diversity programs and similar considerations for the libraries that are a part of the institutions, which initial research indicates to be the case.

\section{Methodology}

To gather data for the study, data related to organizational success of liberal arts colleges and data related to performance in fostering diversity by such colleges were identified, in the form of established rankings based on clearly identified criteria and methodologies that have been tested and refined over time.

To determine an appropriate measure of organizational success that was comparable to that used in the Fortune study and related research, it was determined that an established ranking system, the U.S. News and World Report data, related to organizational success and diversity, would be used in light of its strengths and the limitations of the other ranking sys- 
tems. Data from the two most recently published rankings (i.e., 1999 and 2000) were considered. As a result of the fact that there have been slight changes in the methodologies from year to year, the data were not compared across years but, rather, with institutions being compared to one another using data compiled for each year.

\section{There was no state in the Northeast for which the majority of the colleges were highly rated.}

A database was created that incorporated the data associated with quality (or success) and diversity for each of the institutions listed from the rankings, in the category of liberal arts colleges, with consideration of the actual rank and the rank within ranges (i.e., 1 to 5,6 to 10 , etc.). In addition, data related to the region and the state in which the colleges are located were included to determine whether there were differences based on geographic location of the institutions. A number of types of correlational analysis were undertaken to determine the extent to which various factors had an impact on the quality measures or the diversity rankings.

\section{Findings and Discussion \\ Liberal Arts Colleges}

In total, fifty-seven liberal arts colleges are represented among the rankings of organizational success and of diversity. The U.S. News rankings of organizational success range from a rank of one to fifty, with the scoring making it possible for more than one institution to receive any given rank. The rankings of diversity range from a rank of one to fifteen. As shown in table 1 , the colleges are located in various regions of the country, including more than half in the North (thirty institutions), as well as those in the South (eight), Midwest (nine), and the West (ten). Among the more than twenty states represented, the most frequently identified were New York (nine), Pennsylvania and California (seven each), Massachusetts (six), and Connecticut, Maine, and Ohio (three each).

\section{Diversity and Geographic Location}

Of the fifty-seven liberal arts colleges, only seventeen $(29.8 \%)$ were ranked highly on the basis of diversity in the U.S. News 2000 rankings. A slightly lower percentage (26.3\%) was so ranked in the 1999 rankings. In addition, six of the institutions were ranked highly in relation to diversity but did not appear on the U.S. News 2000 rankings of success, as compared with fifteen colleges in the 1999 data.

A number of factors were considered in relation to the impact on the diversity rankings. For example, the region of the country in which the colleges are located was correlated with significant differences in relation to whether the colleges were rated highly in terms of diversity in both 1999 and 2000. Specifically, seven out of ten of the liberal arts colleges in the West were ranked highly on the basis of diversity in 2000, as compared with approximately one-quarter of the colleges in the North and the South. None of the schools in the Midwest was ranked highly in relation to diversity (table 2). This level of difference among the colleges on the basis of location was represented by a chi square of 0.008 .

The data for 1999 showed similar results, with an even greater level of difference, in that fewer of the colleges in the 
North were related highly in relation to diversity, as represented by a chi square of 0.003 . Again, seven out of the ten colleges in the West were rated highly in relation to diversity, but only 20 percent of the colleges in the North and a quarter of those in the South were so ranked. Also, none of the colTABLE 2

Diversity Ranking by Location: Percentage of Colleges Ranked Highly

leges in the Midwest were rated highly in relation to diversity. In addition, differences approaching significance were noted in relation to the actual diversity rankings of the individual colleges for 2000. In other words, differences related to the actual ranking were identified, as were differences related to whether the schools were rated at all, as discussed above. This finding was also the case with regard to the diversity rankings grouped by categories of 1 to 5,6 to 10 , and 11 to 15 . Similar results related to the rankings by category were noted for the 1999 data, with a chi square of 0.044 , although no such difference was identified in relation to the straight diversity rankings.

With regard to the 2000 data, the individual states in which the colleges were located were correlated with a significant difference in terms of the diversity ranking as well, as represented by a chi square of 0.053 . Specifically, all of the colleges in California were ranked highly in relation to diversity. And none of the institutions in the other western states was ranked highly in relation to diversity, indicating that the colleges in California represent the success related to diversity for liberal arts colleges in the West. With the exception of Georgia, for which both of the colleges were rated highly in relation to diversity, no other colleges in the South were so ranked. There was no state in the Northeast for which the majority of the colleges were highly rated. Again, none of the colleges in the Midwest was rated highly in relation to diversity. Similar results, with an even greater degree of dif- ference (i.e., a chi square of 0.30), are noted with regard to the 1999 data, with all of the colleges in California and Georgia being rated highly in relation to diversity. Again, none of the other institutions in the West or the Midwest were rated highly. And in the northeastern states, there were no instances in which the majority of the colleges were highly rated.

\section{Organizational Success and Diversity}

To determine the extent to which there is a relationship between organizational success and performance related to diversity, a number of types of correlational analysis were undertaken. Specifically, the actual 2000 U.S. News rankings were correlated with whether or not the institutions were rated (i.e., included in the rankings at all) related to diversity. The results indicate that a significant difference was identified, in that the five institutions that were most highly rated in the U.S. News overall rankings of success also were rated highly in terms of diversity. The institutions rated least highly in terms of overall success also were not rated highly in relation to diversity, as represented by a chi square of 0.015 (see table 3).

Similar analyses were undertaken considering whether the colleges were highly rated in terms of diversity and the overall success ranking by category or range ( 1 to 5 and so on). In addition, correlational analyses involving the specific diversity rankings, the diversity rankings by category or range, the specific overall rankings, and the overall rankings by cat- 
TABLE 3

Organizational Success and Diversity: Chi Square Values

\begin{tabular}{lcc} 
& $\begin{array}{c}\text { Overall Ranking: } \\
\text { Specific Ranking }\end{array}$ & $\begin{array}{c}\text { Overall Ranking: } \\
\text { By Category }\end{array}$ \\
\hline Diversity Ranking: Yes or No & 0.015 & 0.000 \\
Diversity Ranking: Specific Ranking & 0.001 & 0.205 \\
Diversity Ranking: By Category & 0.001 & 0.022 \\
\hline
\end{tabular}

egory were undertaken as well. In nearly every correlational measure, significant differences were noted. For example, in the case of the specific diversity rankings as correlated with the specific overall rankings-the correlation that provides for the most detail and specificity of analysis-a chi square value of 0.001 was found. This indicates even more clearly the degree of correlation between institutions that were rated highly in terms of diversity and those rated highly in terms of overall organizational success. Thus, whether the data are considered in relation to the criteria associated with whether the institutions are rated highly at all in terms of diversity (i.e., yes or no), in terms of the specific ranks themselves, or in terms of the ranks within a five-point range, in nearly every instance, the statistical analysis indicates a significant difference.

The institutions that are rated most highly in terms of diversity are also rated highly in relation to other measures of organizational success.

The one instance in which the resulting measure of statistical significance did not indicate a significant level of difference involved the correlation between the overall rankings by category or range and the specific diversity ranking. In addition, these similar tests of correlation did not reveal significant differences in relation to the 1999 data, suggesting a lesser degree of correlation, an effect of the change in the criteria used in the measures of academic excellence from one year to the next, as indicated by the editors or some other factor. However, the number of in- stances of statistically significant correlational statistics provides evidence of the relationship between diversity and organizational success in the academic setting and supports the results of prior research involving private sector organizations. Because the intent of the research presented here is to determine the extent to which there is a relationship between diversity and organizational success at the institutional level, as the basis for further research involving the libraries themselves, the analyses were not intended to be exhaustive but, rather, illustrative.

\section{Summary and Conclusion}

The findings of this study of liberal arts colleges indicate a relationship between diversity and organizational success or performance in the academic environment. The institutions that are rated most highly in terms of diversity are also rated highly in relation to other measures of organizational success. Thus, the results, based on data from established rankings of organizational success and diversity in the academic environment, provide further evidence to support the results of the private sector research on leadership diversity. These results suggest important implications for the academic library, based on the relationship between larger institutional efforts to foster diversity and similar efforts undertaken within the college library. Although it appears that further study is needed to more fully define the nature of the relationship between diversity and organizational success, this and prior research indicate that managerial decisions related to recruitment and hiring efforts taken to (1) target a broad segment of the 
evolving user and potential user population and (2) provide appropriate services for those populations have significant organizational implications and are supported by a rationale that includes pragmatic considerations associated with competitiveness and organizational performance and success.

Results relating to the larger parent institution, as is the case in the private sector research, both inform the overall discussion of diversity as it relates to organizational units such as the library and serve as the basis for further study of the relationship between diversity and organizational success in the academic library. This research is of particular concern in relation to the fact that there is clear evidence that diversity is valued in private sector organizations-the employers of many graduates of colleges and universities. Thus, the findings are of significance in terms of the role of colleges and universities, which includes the educational mission of the academic library, in preparing graduates who can contribute to the success of organizations that have made diversity a priority. Further research should address the nature of the relationship between diversity and organizational success, including the extent to which there is a causal relationship and the extent to which leadership diversity is supported by the prior research associated with theoretical models of leadership, including contingency theory, in order to more fully inform those in the academic library community who have an interest in, and commitment to, diversity and organizational success.

\section{Notes}

1. Geoffrey Colvin, “The 50 Best Companies for Asians, Blacks, and Hispanics: Companies That Pursue Diversity Outperform the S\&P 500. Coincidence?" Fortune 140 (July 19, 1999): 53-54; Sherry Kuczynski, "If Diversity, Then Higher Profits? Companies That Have Successful Diversity Programs Seem to Have Higher Returns. But Which Came First?" HR Magazine 44 (Dec. 1999) [cited 4 April 2001]. Available online from http://www.shrm.org/hrmagazine/articles/ 1299div.htm.

2. Colvin, "The 50 Best Companies for Asians, Blacks, and Hispanics," 54.

3. Kuczynski, "If Diversity, Then Higher Profits?"

4. Ibid.

5. Ibid.

6. Ibid.

7. Ibid.

8. Janice L. Dreachslin and Joseph J. Saunders Jr., “Diversity Leadership and Organizational Transformation: Performance Indicators for Health Service Organizations/Practitioner Application," Journal of Healthcare Management 44 (Nov. /Dec. 1999): 427-39; Gail Warder, "Leadership Diversity," Journal of Healthcare Management 44 (Nov./Dec. 1999): 421-23.

9. Fred E. Fiedler, "Research on Leadership Selection and Training: One View of the Future," Administrative Science Quarterly 41 (June 1996): 43.

10. Martine Duchatelet, "Cultural Diversity and Management/Leadership Models," American Business Review 16 (June 1998): 96-99; Deanne N. Den Hartog, Robert J. House, Paul J. Hanges, S. Antonio Ruiz-Quintanilla, et. al., "Culture Specific and Cross-Culturally Generalizable Implicit Leadership Theories: Are Attributes of Charismatic/Transformational Leadership Universally Endorsed?" Leadership Quarterly 10 (summer 1999): 219-56.

11. Kevin Dobbs, Jack Gordon, Chris Lee, and David Stamps, “Leadership Theories: A Top-10 List," Training 36 (Oct. 1999): 26-27.

12. Janet Z. Burns and Fred L. Otte, "Implications of Leader-Member Exchange Theory and Research for Human Resource Development Research," Human Resource Development Quarterly (Oct. 1, 1999): 225.

13. Boas Shamir and Jane M. Howell, “Organizational and Contextual Influences on the Emergence and Effectiveness of Charismatic Leadership," Leadership Quarterly 10 (summer 1999): 25783; Daniel Goleman, "Leadership That Gets Results," Harvard Business Review 78 (Mar./ Apr. 2000): 78-90.

14. Dobbs, Gordon, Lee, and Stamps, "Leadership Theories," 26.

15. Reginald Shareef, "Ecovision: A Leadership Theory for Innovative Organizations," Organizational Dynamics 20 (summer 1991): 50-63. 
16. Dobbs, Gordon, Lee, and Stamps, "Leadership Theories."

17. Ibid.

18. Daniel Yankelovich, Campus Diversity Initiative (New York: Ford Foundation, 1998).

19. Peter Schmidt, "Federal Judge Upholds Use of Race in Admissions: Michigan Defends Policy by Showing That It Is 'Narrowly Tailored,'” Chronicle of Higher Education 47 (Jan. 5, 2001): A32; Amy Wallace, "UC Regents Refuse to Yield on Affirmative Action Ban," Los Angeles Times, 19 Jan. 1996, A1.

20. Yankelovich, Campus Diversity Initiative.

21. Chronicle of Higher Education Almanac (Washington, D.C.: The Chronicle, 2000-2001).

22. ARL Annual Salary Survey 2000-2001 (Washington, D.C.: Association of Research Libraries, 2000).

23. Mark Winston and Haipeng Li, "Managing Diversity in Liberal Arts College Libraries," College \& Research Libraries 61 (May 2000): 205-15.

24. Robert Franek, ed. The Princeton Review: The Best 331 Colleges (New York: Princeton Review Publishing/Random House, 2000).

25. "About Those College Rankings," Review.Com. [cited 12 February 2001]. Available from http://www.review.com/college/article.cfm?id=college $\backslash$ colAbout.

26. John V. Lombardi, Diane D. Craig, Elizabeth D. Capaldi, and Denise S. Gate, The Top American Research Universities: An Occasional Paper from the Lombardi Program on Measuring University Performance (Gainesville, Fla.: The Center at the University of Florida, 2000).

27. Diane D. Craig, "Top 100 Universities Data for Ten Quality Measures," The Center at the University of Florida [cited 4 April 2001]. Available from http://thecenter.ufl.edu/ research_data.html.

28. "America's Best Colleges 2001: Exclusive Rankings," U.S. News \& World Report 129 (Sept. 11, 2000): 106-23; “America's Best Colleges 2000: Exclusive Rankings," U.S. News \& World Report 127 (Aug. 30, 1999): 88-95; “2001 College Rankings," U.S News Online [cited 4 April 2000]. Available from http://www.usnews.com/usnews/edu/college/corank.htm.

29. "America's Best Colleges 2001," 106-107.

30. Robert J. Morse and Samuel Flanigan, "How We Rank Colleges: Our Method Uses 16 Measures of Academic Excellence," U.S. News Online [cited 4 April 2001]. Available from http:/ / www.usnews.com/usnews/edu/college/rankings/collmeth.htm.

31. "Hispanic Outlook: Top 100," Hispanic Outlook in Higher Education Magazine (May 5, 2000) [cited 14 December 2000]. Available from www.hispanicoutlook.com/top100.html.

32. "Asian American Universities: Best and Worst Universities for Asian Americans," Goldsea Asian American Supersite [cited 12 December 2000]. Available from http://goldsea.com/ AAU.aau.html.

33. "The Progress of Black Student Matriculations at the Nation's Highest-Ranked Colleges and Universities," Journal of Blacks in Higher Education 25 (autumn 1999): 8-16.

34. "Campus Diversity Methodology," U.S. News Online [cited 15 November 2000]. Available from www.usnews.com/usnews/edu/college/rankings/codivers.htm.

35. Winston and Li, "Managing Diversity in Liberal Arts College Libraries," 205.

36. Ibid., 206.

37. Ibid. and Haipeng Li, "Diversity in the Library: What Could Happen at the Institutional Level," Journal of Library Administration 27 (1999): 146. 